\title{
Inflammatory Myofibroblastic Tumor of the Stomach Presenting as an Exophytic Mass - A Diagnostic Dilemma
}

\author{
Meena JADHAV, Rekha HARVI, Rashmi PATIL, Shreekant KITTUR
}

Department of Pathology, Belgaum Institute of Medical Sciences, BELGAVI, INDIA

\begin{abstract}
Inflammatory myofibroblastic tumor is an uncommon soft tissue neoplasm of uncertain biologic behavior, and rarely reported in the stomach. An eighteen-year-old male presented with a mass in the epigastrium of three-month duration. Clinical and radiological examination suggested a gastrointestinal stromal tumor or a leiomyoma in the lesser curvature of the stomach. On the basis of histomorphological features and immunohistochemical analysis the diagnosis of inflammatory myofibroblastic tumor in the lesser curvature of the stomach was made. Inflammatory myofibroblastic tumor should be considered in the differential diagnosis of soft tissue tumors of the stomach.
\end{abstract}

Key Words: Inflammatory myofibroblastic tumor, Inflammatory pseudotumor, Stomach

\section{INTRODUCTION}

Inflammatory myofibroblastic tumors (IMTs) are distinctive mesenchymal neoplasms of intermediate biologic potential that are composed of myofibroblastic spindle cells accompanied by an inflammatory infiltrate of plasma cells, lymphocytes and eosinophils (1). The first IMT was reported in the lungs, in 1937 (2). Common extrapulmonary sites are mesentery, omentum, liver, urinary bladder and retroperitoneum. The tumor shows tendency for local invasion, recurrence, multicentricity and metastasis (3).IMTs are rarely reported in the stomach (4-7). They are usually misdiagnosed clinically and radiologically and pose a diagnostic dilemma even on histopathological examination, which is why we presented this case.

\section{CASE REPORT}

An eighteen-year-old male patient presented with a mass in the epigastrium, loss of appetite and loss of weight of threemonth duration. There was no history of fever, vomiting or hematemesis. On physical examination, the patient was pale and abdominal palpation revealed a firm mass of $9 \times 7 \mathrm{~cm}$ size in the epigastrium and mild hepatomegaly. Hematological investigations revealed hemoglobin level of $8.6 \mathrm{~g} / \mathrm{dl}$, erythrocyte sedimentation rate of $60 \mathrm{~mm} /$ first hour, normal platelet count and microcytic hypochromic anemia. The patient was nonreactive for HIV I and II antibodies. The liver function tests were within normal limits.

(Turk Patoloji Derg 2019, 35:151-156)

Received : 13.01.2017 Accepted : 14.01.2017
Esophagogastroduodenoscopy showed a smooth hemispherical mass in the lesser curvature of the stomach, just below the esophagogastric junction with normal overlying mucosa. A presumptive diagnosis of gastric leiomyoma was made (Figure 1A). The biopsy taken at that time was inconclusive. Computed tomography (CT) scan of the abdomen revealed a large, well defined, thick-walled peripherally-enhancing soft tissue mass of $8.6 \times 7.7 \times 6.8 \mathrm{~cm}$ size in the lesser curvature of the stomach (Figure 1B). The liver was enlarged, showed homogenous density without any space-occupying lesion. Radiological impression was gastrointestinal stromal tumor (GIST). Ultrasound guided FNAC suggested gastric leiomyoma or GIST.

At operation, the mass was exophytic, attached to the lesser curvature of the stomach with a narrow base, and compressing the gastric lumen without invading adjacent structures. There was no regional lymphadenopathy or ascites. The liver was enlarged. No remarkable pathology was observed in the other organs. The mass was excised. On gross examination, the mass was capsulated, measured $9 \times 9 \times 7 \mathrm{~cm}$ with a shiny outer surface and yellowish white, whorled, mucoid cut surface (Figure 1C).

Microscopic examination showed that the tumor was arising from the muscular layer, composed of mildly pleomorphic, spindle to stellate cells arranged singly and in fascicle,s in a background of myxoid, edematous stroma with inflammatory infiltrate of plasma cells and lymphocytes

Correspondence: Meena JADHAV

Department of Pathology, Belgaum Institute of Medical Sciences, BELGAVI, INDIA

E-mail: shubhamj2003@yahoo.co.inＰhone: +91 83124728084 
(Figure 2A,B). The tumor cells had eosinophilic cytoplasm with fusiform nuclei, fine chromatin with tapered to blunt ends, and prominent eosinophilic nucleoli. Mitoses were 1-2/10 HPF. There was no calcification or necrosis. No gastric mucosa could be identified. The surgical margins showed presence of tumor. On immunohistochemistry (IHC) the tumor cells were strongly positive for SMA, MSA (Figure 2C,D), but negative for CD117 (c-KIT), DOG1, CD34, ALK-1, caldesmon, desmin (Figure 3A-F), betacatenin, S-100 protein, CK and EMA.

Based on the above information, a diagnosis of IMT in lesser curvature of the stomach was rendered. The patient is doing well without any evidence of disease, five years after surgery.

\section{DISCUSSION}

Inflammatory myofibroblastic tumor (IMT) has been named as inflammatory pseudotumor, inflammatory myofibroblastic proliferation, plasma cell granuloma or inflammatory myofibroblastoma (4). Now it is classified under intermediate neoplasms in World Health Organization, Histological Typing of Soft Tissue Tumors (8). It is rare in the gastrointestinal tract, with ileocaecal region and stomach as the common sites (9). There are
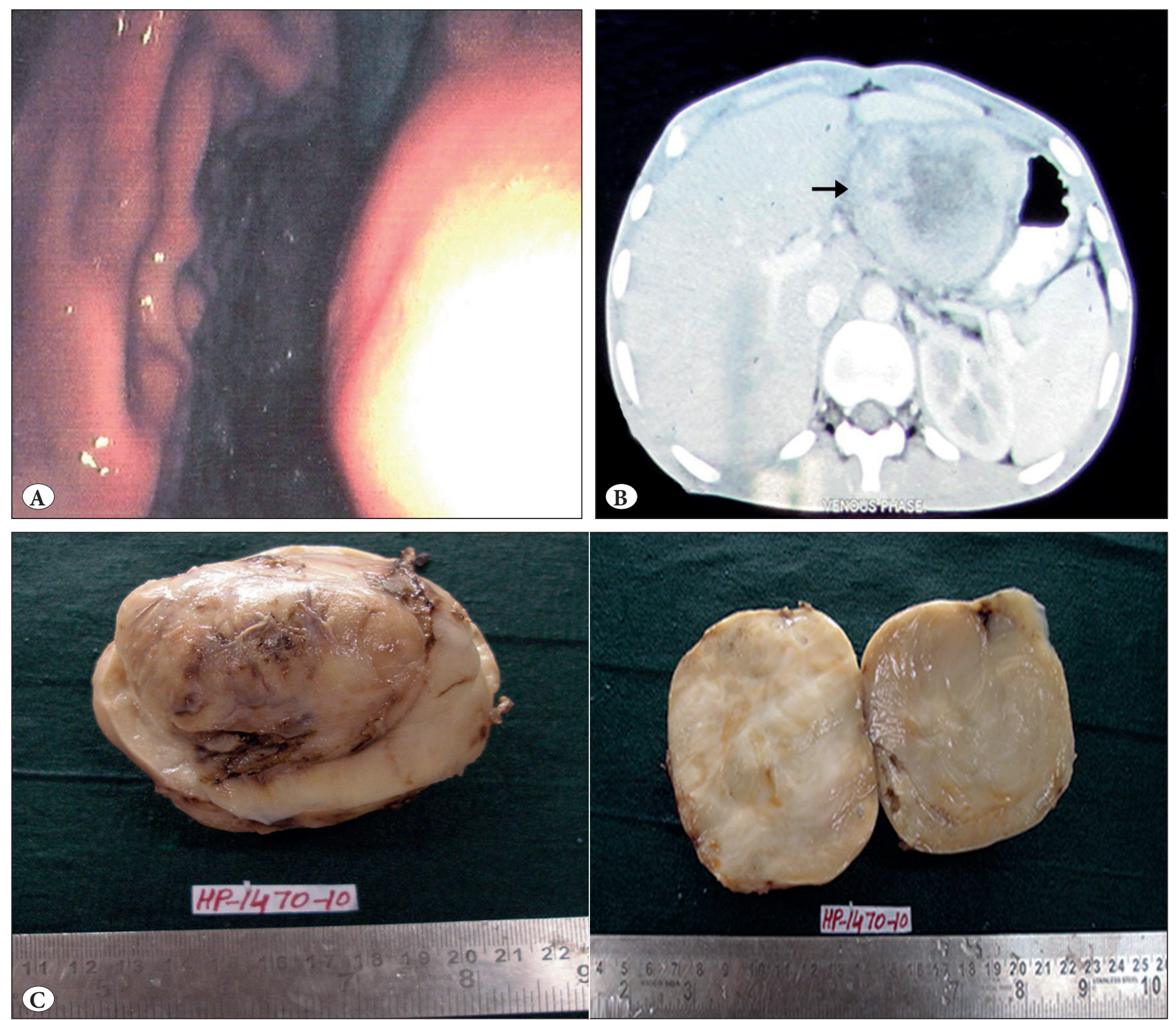

Figure 1: A) Endoscopic image showing the gastric mass. B) CT scan showing soft tissue lesion arising from the wall of the stomach. C) Gross photograph of the mass with shiny outer surface and whorled, mucoid cut surface. 
about 34 gastric IMT cases reported in the English literature. The clinicopathological features of these 34 cases are summarized in Table I (2,4-7,10-13). The age at diagnosis ranged from 4 months to 80 years (mean 27.2 years). Females were more commonly affected than males. The common symptoms were abdominal pain and abdominal mass. The mean tumor size was $6.9 \mathrm{~cm}$. In the stomach, IMT was frequently reported in the body of the stomach but involvement of lesser curvature with exophytic mass formation was rare $(4,7)$. Follow up data was available in 26 cases with duration of follow up time ranging from 1 month to 14 years (mean 2.7 years). Recurrence was seen in 4 cases out of 26 cases reviewed in the literature.
The etiology of IMT is unknown $(2,4,6)$. The various mechanisms postulated were secondary to trauma, surgery, immunological diseases or infections like mycobacteria, Epstein-Barr virus, actinomycetes, Nocardia and Helicobacter pylori (9). In the present case, there was no past history of serious illness, trauma, gastritis, gastric endoscopy or biopsy. Recent studies have demonstrated clonal cytogenetic aberrations with rearrangement of ALK gene on chromosome $2 \mathrm{p} 23$ in $50 \%$ to $70 \%$ of cases, suggesting a neoplastic origin for IMT (1).

The present case of IMT, posed a diagnostic dilemma in differentiating it from GIST and inflammatory fibroid polyp (IFP). GISTs typically do not show inflammatory
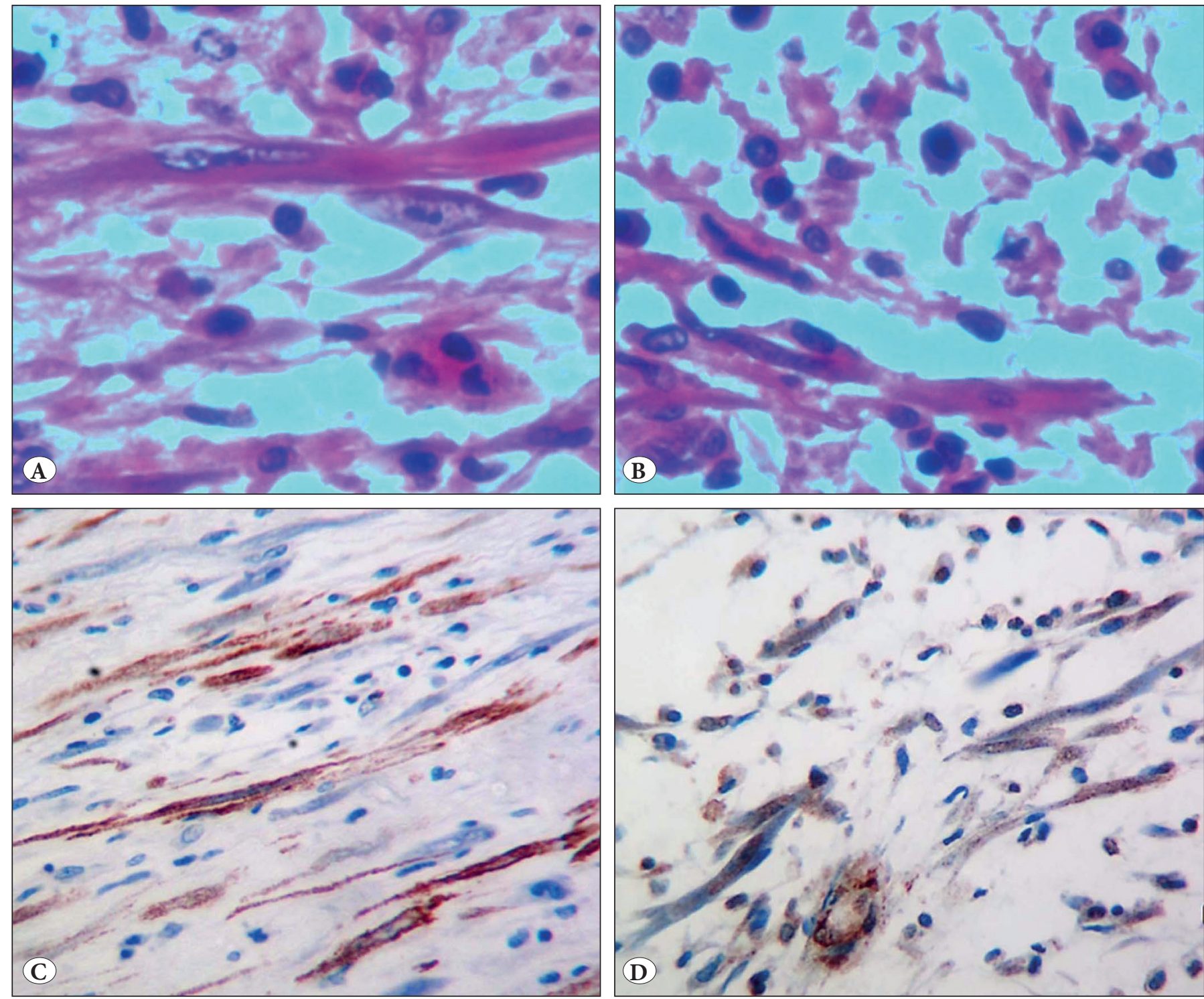

Figure 2: A,B) Atypical spindle cells in an edematous stroma with plasmacytic and lymphocytic infiltration (H\&E; x400). C) Tumor cells are immunopositive for SMA (x200) and D) MSA (x200). 
background as is seen in IMTs. They frequently show skeinoid fibers that were not seen in the present case. On IHC the GISTs are strongly positive for CD117, DOG1 and CD34 but negative for ALK-1 whereas IMT shows an opposite profile. In the present case, the tumor cells were negative for CD117, DOG1 and CD34. They were strongly positive for SMA, MSA but negative for ALK-1, caldesmon and desmin hence favoring a diagnosis of IMT over GIST. Though ALK positivity is helpful in the diagnosis of IMT, it is only seen in $56 \%$ of the cases. ALK negative IMTs are said to be associated with the presence of greater pleomorphism, atypical mitosis and distant metastasis, but not local recurrence (1). The present case did not show atypical mitosis and there is no evidence of metastasis five years after surgery. Inflammatory fibroid polyps (IFP) are typically submucosal and show granulation tissue like stroma and eosinophil rich infiltrate with perivascular cuffing contrary to IMTs that show less eosinophils and more lymphocytes. Most of these lesions show spindle cells positive for CD34, whereas tumor cells of IMTs are negative for CD34 and positive for actins. The present case did not show eosinophils or perivascular cuffing and tumor cells were negative for CD34.
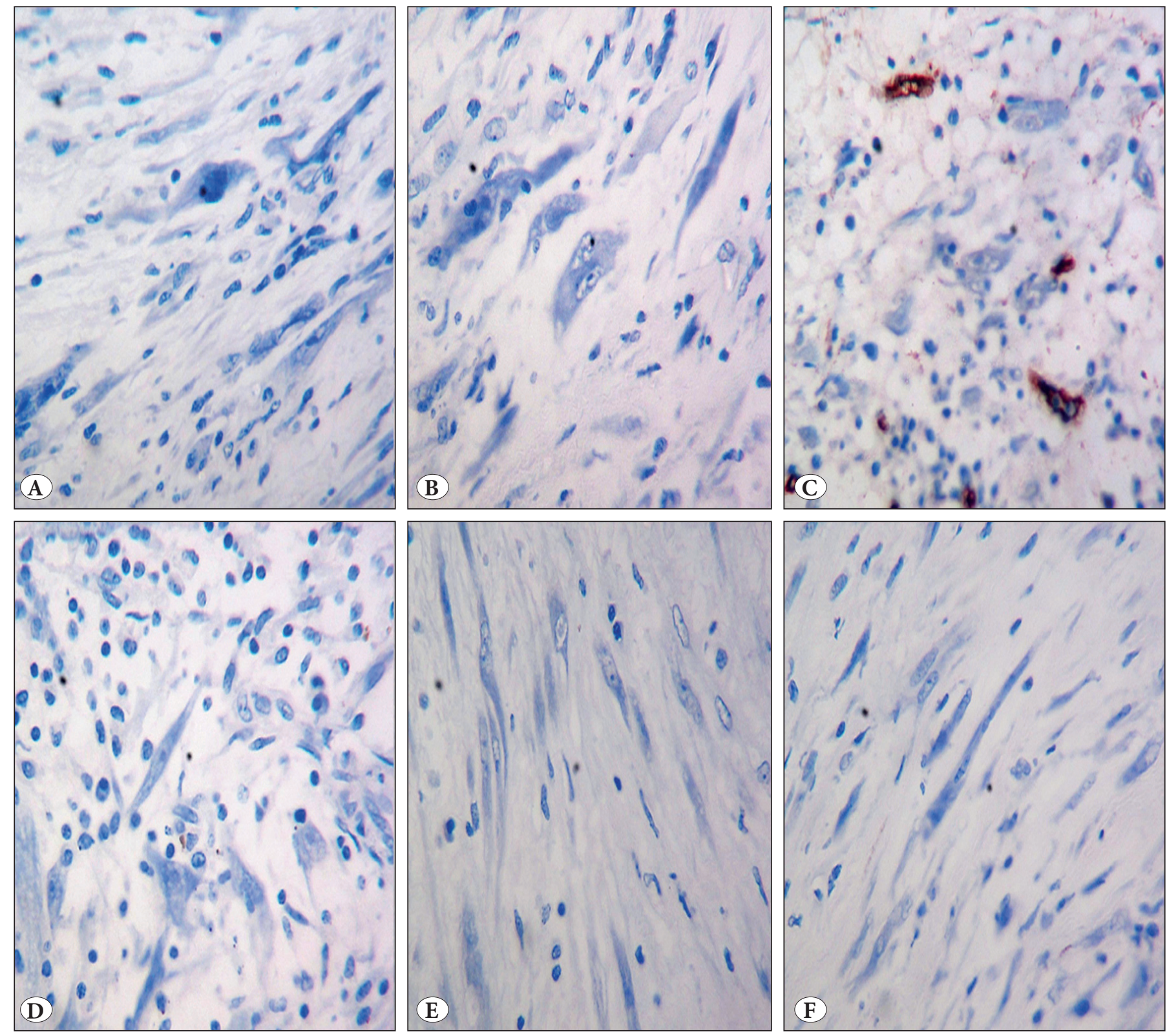

Figure 3: Microphotograph showing tumor cells negative for A) CD117 (x200), B) DOG1 (x200), C) CD34 (x200), D) ALK-1 (x200), E) Caldesmon (x200) and F) Desmin (x200). 
Table I: Clinicopathological features of 34 previously reported cases of gastric IMTs

\begin{tabular}{lc}
\hline Parameter & Distribution of cases \\
\hline Age: Range & 4 months -80 years (Mean -27.2 years) \\
\hline Males: Females & $10: 24$ \\
\hline Presentation: & 11 \\
Abdominal pain & 4 \\
Abdominal pain and Abdominal mass & 3 \\
Abdominal mass & 3 \\
Vomiting & 3 \\
Gastrointestinal bleeding & 3 \\
Dysphagia & 3 \\
Fever & 2 \\
Weakness & 2 \\
NA & $1.5-11 \mathrm{~cm}(\mathrm{Mean} 6.9 \mathrm{~cm})$ \\
\hline Size: Range & \\
Sites: & 18 \\
Body & 5 \\
Cardia & 4 \\
Fundus & 3 \\
Pyloric antrum & 2 \\
Pylorus & 2 \\
NA & \\
\hline Outcome: & 22 \\
No recurrence & 4 \\
Recurrence & 8 \\
NA & \\
\hline
\end{tabular}

NA: Not available in the literature reviewed.

Other differential diagnoses considered were leiomyoma, polyps with bizarre stromal cells, solitary fibrous tumor, fibromatosis, peripheral nerve sheath tumor and follicular dendritic sarcoma but were excluded based on the routine microscopic and IHC findings. Inflammatory fibrosarcoma may be related to IMT, as it shares similar clinical and pathological features (14).

There are no definite clinical, microscopic or genetic features to predict the recurrence or metastasis (1). They may undergo spontaneous regression (8). Gastric IMTs have relatively good prognosis as the recurrence rate is $15 \%$ to $37 \%$ within a year after surgery (7). Complete surgical excision is the treatment of choice with long-term follow-up $(2,4,9)$. Chemotherapy and radiotherapy are advocated for cases with recurrence or metastasis (1). To conclude, IMT have a relatively good prognosis, and should be considered in the differential diagnosis of soft tissue tumors in the stomach to avoid unnecessary aggressive therapy.

\section{REFERENCES}

1. Coffin CM, Hornick JL, Fletcher CDM. Inflammatory myofibroblastic tumor: Comparison of clinicopathologic, histologic and immunohistochemical features including ALK expression in atypical and aggressive cases. Am J Surg Pathol. 2007;31:509-20.

2. Sanders BM, West KW, Gingalewski C, Engum S, Davis M, Grosfeld JL. Inflammatory pseudotumor of the alimentary tract: Clinical and surgical experience. J Pediatr Surg. 2001;36:169-73.

3. Coffin CM, Watterson J, Priest JR, Dehner LP. Extrapulmonary inflammatory myofibroblastic tumor (Inflammatory pseudotumor): A clinicopathologic and immunohistochemical study of 84 cases. Am J Surg Pathol. 1995;19:859-72.

4. Katakwar A, Gedam BS, Mukewar S, Agasti A. Primary gastric inflammatory myofibroblastic tumor in an adult - case report with brief review. Indian J Surg Oncol. 2014;5:66-70.

5. Huang WH, Cheng SM, Shih SL, Yang FS. Inflammatory myofibroblastic tumor of the stomach: A rare case report. J Radiol Sci. 2012;37:79-81.

6. Qiu JF, Shi YJ, Fang L, Wang HF, Zhang MC. High fever as an initial symptom of primary gastric inflammatory myofibroblastic tumor in an adult woman. Int J Clin Exp Med. 2014;7:1468-73. 
7. Cho MY, Min YK, Kim NR, Cho SJ, Kim HK, Lee KC, Suh SO, Whang CW. Fever of unknown origin as a presentation of gastric inflammatory myofibroblastic tumor in a two year old boy. J Korean Med Sci. 2002;17:699-703.

8. Coffin CM, Patel A, Perkins S, Elenitoba-Johnson KSJ, Perlman E, Griffin CA. ALK 1 and p80 expression and chromosomal rearrangements involving 2 p23 in inflammatory myofibroblastic tumor. Mod Pathol. 2001;14:569-76.

9. Narla LD, Newman B, Spottswood SS, Narla S, Kolli R. Inflammatory pseudotumor. Radiographics. 2003;23:719-29.

10. Karnak I, Senocak ME, Ciftci AO, Caglar M, Bingol - Kologlu M, Tanyel FC, Buyukpamukcu N. Inflammatory myofibroblastic tumor in children: Diagnosis and treatment. J Pediatr Surg. 2001;36:908-12.
11. Al-Taie OH, Mork H, Jenett M, Klein D, Muller JG, Scheurlen M. Fast growing gastric inflammatory pseudotumor: A rare manifestation of peptic ulcer disease. Endoscopy. 2002;34:239.

12. Park SH, Kim JH, Min BW, Song TJ, Son GS, Kim SJ, Lee SW, Chung H, Lee JH, Um JW. Exophytic Inflammatory myofibroblastic tumor of the stomach in an adult women: A rare cause of hemoperitoneum. World J Gastroenterol. 2008;14:1369.

13. Kim KA, Park CM, Lee JH, Cha SH, Park SW, Hong SJ, Seol HY, Cha IH, Mok YJ, Kim YS. Inflammatory myofibroblastic tumor of the stomach with peritoneal dissemination in a young adult: Imaging findings. Abdom Imaging. 2004;29:9-11.

14. Coffin CM, Dehner LP, Meis-Kindblom JM. Inflammatory myofibroblastic tumor, inflammatory fibrosarcoma and related lesions: An historical review with differential diagnostic considerations. Semin Diagn Pathol. 1998;15:102-10. 